\title{
Estimating the potential for selective collection of biowaste in Romania and the capitalization by anaerobic digestion
}

\author{
Lucia Varga ${ }^{1}$, Ioana Ionel ${ }^{2}$, Gheorghe Zaman ${ }^{3}$, Emilia Dunca ${ }^{4}$, and Ramon \\ Mihai Balogh ${ }^{5}$, \\ ${ }^{1}$ Institute of National Economy, Bucharest, Romania, \\ ${ }^{2}$ Politehnica University Timisoara, Faculty of Mechanical Engineering, \\ ${ }^{3}$ Institute of National Economy, Bucharest, Romania, \\ ${ }^{4}$ Petrosani University, Faculty of Mines, \\ ${ }^{5}$ Politehnica University Timisoara, Faculty of Mechanical Engineering.
}

\begin{abstract}
The aim of the paper is to make an x-ray of the potential of biological waste collection for the production of biofuels and fertilizers in Romania. It presents the existing legislative framework on bio-waste management as well as recycling technologies. A case study on the evaluation of the potential for selective collection of bio-waste for its anaerobic digestion is described.
\end{abstract}

Keywords: biowaste, circular economy, anaerobic digestion, biogas, bioeconomy

\section{Introduction}

Global problems such as climate change, depletion of natural resources, destruction of biodiversity and massive environmental pollution are the challenges facing humanity today. „Improving health and environmental conditions, conducting research projects related to waste recycling and environmental sustainability, as well as promoting environmental awareness in urban areas" [13] are objectives that can be achieved through social responsibility.

To meet these challenges, it is necessary to adopt new concepts such as sustainable development, the circular economy and sustainable and circular bio-economy. They require a change in production and consumption patterns.

It is necessary to apply new technologies that ,meet two conditions: natural resources should be used at rates that ensure long-term supply so that they do not run out unacceptably "and," waste should be generated at lower rates than can be easily assimilated by the natural environment [17].

The circular economy policy package focuses on the closure of material loops through recycling and reuse of products. This reduces the quantities of raw materials used and therefore the pressure on the environment by extracting and processing ores to obtain them.

The transition from a linear to a circular economy model required for materials is based on the recovery of products and materials at the end of the product life cycle by connecting waste to resources. This will give the European economy a competitive advantage and reduce dependence on imports of raw materials from outside the European area [5].

The basic principles of the circular economy are complementary to the bio-economy. In addition, the bioeconomy launches a strong perspective on renewed competitiveness, developing through innovation low-carbon and resource-efficient goods and services [15]. 
The bio-economy aims to improve the exploitation of biomaterials in a sustainable way and pays little attention to the aspects of green design, waste management and recycling and the role of innovative business models in this regard [12].

These new economic models pay special attention to the recovery of biowaste. Biodiesel is a biodegradable waste from gardens and parks, food and kitchen waste from households, offices, restaurants, wholesale warehouses, canteens, catering companies or retail stores and comparable waste from product processing plants, food [1].

In 2015, the European Commission adopted the Circular Economy Package with the aim of conserving resources and sustaining a sustainable economy by boosting waste recycling and recovery. Minimizing waste generation and keeping products as economical as possible are two goals set for the development of a „sustainable, low-carbon, resource-efficient and competitive economy” [4]. The composition of household waste generated at European level is presented in figure 1. It is observed that biowaste represents $31 \%$ of the total.

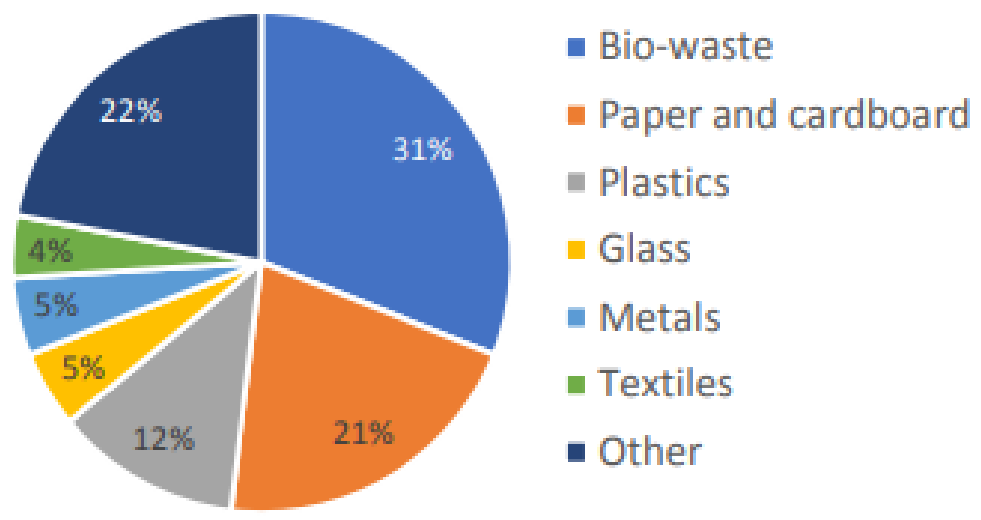

Figure1 Composition of household waste in Europe [14].

According to the waste hierarchy, established at the level of the European Commission, one concluded that the management must be done in the following order: prevention of waste generation, preparation for reuse, recycling, recovery; preparation for reuse, recycling; recovery, for example energy recovery; elimination [2].

In 2017, the document „The role of energy recovery in waste in the circular economy” was drafted COM (2017) 34 final, by which the European Commission recommends Member States to recover energy only if it cannot be recycled or reused [7]. The waste disposal technologies recommended by the Commission are: its co-incineration in cement plants or large combustion plants as well as incineration in incinerators for waste incineration or indirect incineration following pyrolysis or gasification. Also, the anaerobic digestion technology of biodegradable waste or the productions of waste fuels are increasingly used for waste disposal. [7].

In order to analyze the technologies for capitalizing on biowaste, a comparative study was conducted on the different treatment methods for municipal organic waste [3]. The study occurred in seven cities with different population numbers (Zagreb, Skopje, Malaga, Paris, Ivanic, Krk and Madrid). Tools and methodologies for the separate collection of food waste have been developed and information has been provided on technical, economic and environmental aspects of anaerobic digestion of biowaste and biofuel production.

Also, the existing obstacles regarding the possibility of using biowaste for biomethane production were identified, these being related to the poor public perception and lack of knowledge regarding the separate collection of biowaste and the potential for energy generation from biogas.

Awareness campaigns were carried out in which the economic, social and environmental benefits generated by the separate collection of waste, its anaerobic digestion and the production of biofuel were presented. 
The research also developed a reference tool to compare the value chain of diversion of biowaste to biomethane with other value chains of waste treatment, such as landfills, composting and incineration. Thus, the positive benefits of anaerobic digestion of biowaste have been highlighted, proving to be a standard technology for treating organic waste collected separately. [3] The comparative analysis carried out took into account aspects such as reducing the total waste generated, increasing the safe energy supply, recycling nutrients, reducing greenhouse gas emissions. The study showed that anaerobic digestion is the technology of recovery of biowaste considered the best and environmentally friendly [3]. Other research proved that anaerobic digestion of separately collected bio-waste is a recycling technology. In the situation when a separate collection of bio-waste, is achieved, and further it is turned by anaerobic digestion to biogas and digestate, a successful industrial circle is closed. The result consists both of a bio-fuel (renewable energy sourse neutral in $\mathrm{C}$ emission) and a natural fertilizer that meets the quality standards to be used successfully in agriculture [7]. Anaerobic digestion is also considered a biotechnology through which they can simultaneously generate bioenergy (such as methane biogas), but simultaneously reduce environmental the pollution and contribute to generate recycled nutrients. [16]

\section{Recovery of biowaste at national level}

Romania approved Decision no. 3/2016 on the Circular Economy Package: COM (2015) 614 final [6], which transposes the legislation in the field developed at European level. This normative act establishes priority actions for the transition of the circular economy. These actions address production, consumption, innovation and investigation, waste management and the creation of a market for secondary raw materials. "[6]

Also, Law no. 181 of 19 August 2020 on the management of compostable non-hazardous waste [10] which obliges local authorities to implement, from 1 January 2021, the implementation of a separate collection system for biodegradable waste, extends the separate door-to-door collection of bio-waste in the environment urban.

At the same time, it is recognized that for Romania, the targets for recycling and preparation for reuse of municipal waste (60\% in 2025 and 65\% in 2030) and packaging waste (no special target yet), to reduce municipal waste storage at a maximum of $10 \%$ in 2030 will remain a challenge, although for the latter Romania is included in the group of Member States that will benefit from derogations " [6].

In order to achieve waste management targets, it is necessary to establish a national structure for the separate collection of recyclable waste, biowaste and residual waste, the transport, sorting, recovery, recycling and storage. In the National Waste Management Plan [9], all the costs necessary for making investments and for operating in the vision of proper waste management, for the period 2018-2025 were estimated. Consolidated financial flows, for 2018 - 2025 are centralized in Table 1 [9].

As it can be seen, the investments required for the construction of separate biowaste collection infrastructure were estimated at 66.472 million euros and for the construction of composting facilities 3.940 million euros and for the construction of anaerobic biowaste digestion facilities 278.250 million euros. [9].

The choice of waste recovery technologies, their design, construction and operation will be made taking into account the existing situation regarding diferent aspects, such as: waste management, real assessment of waste quantities generated, their generation forecast based on population growth forecast, estimation of biowaste collection potential and of the targets provided by the legislation. This information is part of the County Waste Management Plans which is a strategic tool for assessing and planning waste management for a set time horizon. Currently, in Romania, there are regulations, guidelines and procedures for the assessment and planning of waste management, but there are no guidelines and procedures for estimating the potential for separate collection of biowaste and the recovery for biogas. 
Table 1. Consolidated financial flows, 2018 - 2025, [9]

\begin{tabular}{|c|c|c|c|c|c|c|c|c|c|}
\hline \multicolumn{10}{|c|}{ Financial flows (million euros) } \\
\hline Indicator & Total & 2018 & 2019 & 2020 & 2021 & 2022 & 2023 & 2024 & 2025 \\
\hline \multicolumn{10}{|l|}{ A.Investment } \\
\hline \multicolumn{10}{|l|}{$\begin{array}{l}\text { A.1. Collection } \\
\text { and transport }\end{array}$} \\
\hline $\begin{array}{l}\text { Separate recyclable } \\
\text { collection }\end{array}$ & 182,476 & - & 178.833 & 3,643 & - & - & - & - & - \\
\hline $\begin{array}{l}\text { Separate } \\
\text { biodegradable } \\
\text { collection }\end{array}$ & 66,472 & - & 66,472 & - & - & - & - & - & - \\
\hline Residual collection & 41,659 & - & 41,659 & - & - & - & - & - & - \\
\hline $\begin{array}{l}\text { Total collection and } \\
\text { transport }\end{array}$ & 290,606 & - & 286,963 & 3,643 & - & - & - & - & - \\
\hline \multicolumn{10}{|l|}{$\begin{array}{l}\text { A.2. Fixed } \\
\text { investment }\end{array}$} \\
\hline Transfer & - & - & - & - & - & - & - & - & - \\
\hline Composting & 3,940 & 1,182 & 2,758 & - & - & - & - & - & - \\
\hline $\begin{array}{l}\text { Sorting - separately } \\
\text { recycled waste }\end{array}$ & 4,930 & 1,479 & 3,451 & - & - & - & - & - & - \\
\hline $\begin{array}{l}\text { TMB with } \\
\text { biostabilization }\end{array}$ & - & - & - & - & - & - & - & - & - \\
\hline Anaerobic digestion & 278,250 & 83,475 & 194,775 & - & - & - & - & - & - \\
\hline TMB with bio drying & 226,636 & - & - & 24,484 & 135,982 & 66,171 & - & - & - \\
\hline $\begin{array}{l}\text { incineration with } \\
\text { energy recovery }\end{array}$ & 136,324 & - & - & 13,632 & 81,794 & 40,897 & - & - & - \\
\hline $\begin{array}{l}\text { other investment } \\
\text { costs }\end{array}$ & 112,503 & 43,280 & 23,633 & 11,782 & 15,221 & 11,290 & 7,297 & - & - \\
\hline $\begin{array}{l}\text { Total fixed } \\
\text { investment }\end{array}$ & 762,583 & 129,415 & 224,617 & 49,898 & 232,997 & 118,358 & 7,297 & - & - \\
\hline \multicolumn{10}{|l|}{ A.3 Deposit } \\
\hline Extension deposits & 80,740 & 49,213 & - & 1,538 & 1,922 & - & 10,765 & 11,15 & 6,152 \\
\hline $\begin{array}{l}\text { Closing non- } \\
\text { compliant deposits }\end{array}$ & 15,600 & 13,200 & 2,400 & - & - & - & - & - & - \\
\hline Total deposit & 96,340 & 62,413 & 2,400 & 1,538 & 1,922 & - & 10,765 & 11,15 & 6,152 \\
\hline
\end{tabular}

\section{Separate collection of biowaste in Romania.}

In Romania no qualified separate collection system for diferent biowaste categories nor the infrastructure necessary for their recovery, although the obligation to make them is provided in the legislation, are turned into reality, even a start happened

In order to estimate the potential for separate collection of biowaste suitable for treatment by anaerobic digestion and the potential for individual composting, in Ilfov County, a study was conducted in 2020 using a statistical analysis of research and data processing.

In the following the results of the study used, and the appropriate dimensioning of the infrastructure for the separate collection of biowaste and for the design and operation in view of the of the recovery facilities by anaerobic digestion are revealed. The stratified probabilistic selection of the authorized legal entities was made by using the mechanical measurement step for 100 units, the data collection duration was 2 weeks, the data collection procedure was the face-to-face interview. 
The study estimated the quantities of food waste generated in the retail and other forms of distribution, the quantities of food waste generated by restaurants and food services and the quantities of biowaste generated by households, the potential for a separate collection and the potential. individual composting [18]. There was also the potential for their separate collection. The study was carried out only for 3 of the 5 activities provided in the food supply chain, According to EC Decision 2019/1597 supplementing Directive 2008/98 / EC of the European Parliament and of the Council [11]. The waste generated from the primary production and from the food processing and production activity was not estimated. For the estimation of the quantities of food waste generated in the retail and other forms of distribution stage and for those generated from restaurants and food services and the separate collection potential used, minimum samples were established and the estimation of the quantity of food waste was performed. through the method of questionnaires and interviews.

In order to establish the minimum samples, the units authorized at the level of Ilfov County were taken into account, the main data source being the existing one at the Veterinary Health and Food Safety Directorate of Ilfov.

The questionnaires include questions regarding the biowaste generated (regarding the categories of food waste generated, the collection method used, the economic operator taking over, the estimated quantities), the availability of the generator to collect the bio-waste separately, the availability to hand over the separately collected bio-waste to the to the local public authority within which the unit is located [18].

After applying the questionnaire to the units in the established sample, the data were processed and extrapolated to the entire category, for each category in order to obtain an estimate for the entire county. [18]

To estimate the quantities of biowaste generated by households, the potential for separate collection and the potential for individual composting, the rural and urban localities were selected that meet the conditions for separate collection of biowaste, a minimum sample was established depending on the number of households and the quantities of biowaste were estimated by the method of questionnaires and interviews. [18]

The questionnaire was briefed on: the number of members per household, the quantities of biowaste estimated to be generated in the household, whether the generated biowaste is used as animal feed and in what proportion, the willingness to collect biowaste separately in the future.

After applying the questionnaire to the households in the established sample, the data were processed and extrapolated to all households in the respective area of residence. [18]

The results obtained are centralized in table 2.

Regarding the availability regarding the separate collection of food biowaste for anaerobic treatment, in the case of supermarkets it is over $97 \%$ and $88.6 \%$ in the case of stores. Thus, the potential for separate collection from the category of retail units and other forms of distribution is close to the values generated, the total quantity that is estimated to be collected separately being approximately 2,776.4 tons / year.

Table 2 Quantities of biowaste generated by retail outlets and other forms of distribution [18]

\begin{tabular}{|c|c|c|c|}
\hline $\begin{array}{l}\text { Sources of biowaste } \\
\text { generation }\end{array}$ & Total units & $\begin{array}{l}\text { Quantities of biowaste } \\
\text { generated }\end{array}$ & $\begin{array}{l}\text { Potentially collected } \\
\text { quantities separately }\end{array}$ \\
\hline Mixed store & 2024 & 2001,3 & 1772,6 \\
\hline Supermarket & 115 & 1031,7 & 1003,8 \\
\hline Total units & 2139 & 3033,0 & 2776,4 \\
\hline
\end{tabular}

The quantities of food waste generated by restaurants and food services and the potential for separate collection are centralized in Table 3. The potential for separate collection of food bio-waste for treatment by anaerobic digestion is $98,4 \%$ 
Table 3. Quantities of biowaste generated by restaurants and other food services [18]

\begin{tabular}{llll}
\hline Sources of biowaste generation & Total units & $\begin{array}{c}\text { Quantities of } \\
\text { biowaste generated }\end{array}$ & $\begin{array}{c}\text { Potentially collected } \\
\text { quantities } \\
\text { separately }\end{array}$ \\
\hline Restaurant & 328 & $1.066,7$ & $1.049,6$ \\
Fast Food & 520 & $1.691,0$ & 1664 \\
Catering & 126 & 409,8 & 403,2 \\
Pizzerie & 70 & 227,6 & 224,0 \\
Canteens & 276 & 897,6 & 883,2 \\
Total units & 1320 & $4.292,6$ & $4.224,0$ \\
\hline Change in activity volume 2020/2019 & $6.694,7$ & $6.587,6$ \\
\hline
\end{tabular}

Estimation of quantities of biowaste generated by households, separate collection potential and individual composting potential

To estimate the quantities of biowaste generated by households, the potential for separate collection and the potential for individual composting, a number of 484 questionnaires were applied, of which $53.3 \%$ in urban areas and $46.7 \%$ in rural areas [18]. The estimated food waste quantities in Ilfov County, generated annually, are centralized in Table 4 [18].

Table 4 Quantities of biowaste, households [18]

\begin{tabular}{llll}
\hline $\begin{array}{c}\text { Sources of biowaste } \\
\text { generation }\end{array}$ & $\begin{array}{c}\text { Total number of } \\
\text { households }\end{array}$ & $\begin{array}{c}\text { Quantities of } \\
\text { biowaste generated }\end{array}$ & $\begin{array}{c}\text { Potentially collected } \\
\text { quantities separately }\end{array}$ \\
\hline Urban & 79.353 & $24.224,8$ & $18.778,9$ \\
Rural & 95.606 & $26.249,6$ & $13.705,5$ \\
\hline Total & 174.959 & $50.474,4$ & $32.484,5$ \\
\hline
\end{tabular}

The obtained results are then extrapolated to all sales units, restaurants and other food services authorized by Ilfov County.

Also, the centralized results in table 3 will be used to determine the quantities of biowaste for which the centralized waste collection is desired for all localities of the project area.

\section{Conclusions}

The paper aimed to make an x-ray of the potential of biowaste for the production of biofuels and fertilizers, based on state of art information and data specific to Romania. Also it focusses on the existing legislative framework on biowaste management, as well as their recovery technologies, and finally to describe a case study regarding the evaluation of the potential for selective collection of biowaste, in view of the valorizasion through anaerobic digestion.

The conclusions that emerge are:

- Separate collection of biological waste and its recovery by anaerobic digestion and transformation of biogas into biofuel is considered the most environmentally friendly technology in a circular and sustainable bioeconomy.

- Recycling of biological waste can only be done if it is collected separately to recover it by anaerobic digestion and obtaining biogas and fertilizer.

- It is recommended to carry out separate collection of bio-waste for all 5 activities provided in the food supply chain, respectively organic waste from primary production and food processing and production, retail and other forms of distribution, restaurants and food services and households; Currently, there are no measurement data on the quantities of biowaste generated at the source.

- Estimation of the quantities of biowaste generated can be done by statistical methods.

- In order to collect data on the quantities of biowaste generated and on the availability of separate collection and their delivery for anaerobic digestion, questionnaires and interviews can be conducted. 
By centralizing and processing the data, the estimation of the quantities of biowaste generated and of the potential for their separate collection for the established samples is obtained.

At the county level, the quantities of biowaste generated from the activities of retail and other distribution of food, restaurants and food services and from households can be estimated by extrapolating the data obtained for samples to all authorized economic agents and to all the population of the respective county.

Based on the obtained data, the system for the separate collection of biowaste and the intrastructure of transport and capitalization by anaerobic digestion are designed. If the necessary investments are made to transform the biogas obtained into biofuel, it can be marketed or used for fueling biodiesel transport vehicles, which would significantly reduce the total costs of biowaste management.

\section{Acknowledgement:}

The authors would like to thank the partners and stakeholders of the DECIDE project - ,, Development through entrepreneurial education and innovative doctoral and postdoctoral research" for their effort and contribution. The project is co-financed from the European Social Fund through the Human Capital Operational Program 2014-2020. We also thank the Ilfov County Council for access to data on the separate collection of biowaste.

\section{References}

[1] Directive 2008/98 / EC of the European Parliament and of the Council on waste and repealing certain Directives, Official Journal of the European Union, https://eurlex.europa.eu/legal-content/RO/TXT/HTML/?uri=CELEX:32008L0098\&from =RO

[2] Law no. 31/2019 on the approval of the Government Emergency Ordinance no. 74/2018 for the amendment and completion of Law no. 211/2011 on the waste regime, of Law no. 249/2015 on the management of packaging and packaging waste and Government Emergency Ordinance no. 196/2005 on the Environmental Fund, https://www.legeonline.ro/lr-LEGE-31\%20-2019-(209958)-(1).html

[3] Bin2Grid, file:///C:/Users/Hp/Desktop/Attachment 0\%20(1).pdf

[4] COM (2015) 614 final - Closing the loop - an EU action plan for the circular economy, https://eurlex.europa.eu/legalcontent/RO/TXT/HTML/?uri=CELEX:52015DC0614\&from $=R O$.

[5] Isabel Garcia Herrero, Maria Margallo, Raquel Onandia, Ruben Aldaco, Angel Irabien, Conecting wastes to resources for clen technologies in the chlor-alkali industry: a life cycle approach, Clean Technologies and Environmental Policy, Volume 2, march 2018.

[6] Decision No 3 of 2 February 2016 on the Circular Economy Package: COM (2015) 614 final Communication from the Commission to the European Parliament, the Council, the European Economic and Social Committee and the Committee of the Regions „Closing the loop - an EU action plan for the circular economy", COM (2015)593 final, http://www.cdep.ro/pls/legis/legis_pck.htp_act?ida=135136.

[7] Communication from the Commission to the European Parliament, the Council, the European Economic and Social Committee and the Committee of the Regions - The role of energy recovery in the circular economy COM (2017) 34 final, Brussels, 26.1.2017 COM (2017) 34 final, https://ec.europa.eu/transparency/regdoc/rep/1/2017/RO/COM-2017-34-F1RO-MAIN-PART-1.PDF

[8] Green Paper on the management of bio-waste in the European Union, 2008, https://eurlex.europa.eu/legal-content/RO/TXT/HTML/?uri=CELEX:52008DC0811\&from $=$ RO

[9] DECISION no. 942 of December 20, 2017 regarding the approval of the National Waste Management Plan, http://legislatie.just.ro/Public/DetaliiDocument/196382 
[10] Law no. 181 of 19 August 2020 on the management of compostable non-hazardous waste, OFFICIAL GAZETTE no. 762 of August 20, 2020

[11] Commission Decision (EU) 2019/1597 of 3 May 2019 supplementing Directive 2008/98 / EC of the European Parliament and of the Council as regards a common methodology and minimum quality requirements for the uniform measurement of food waste levels, Official Journal of the European Union L 248/77, https:/leur-lex.europa.eu/legalcontent/RO/TXT/PDF/? uri=CELEX:32019D1597\&from $=$ EN

[12] The circular economy and the bioeconomy Partners in sustainability, EEA Report No 8/2018, https://www.eea.europa.eu/publications/circular-economy-and-bioeconomy

[13] Evaluating Circular Economy under a Multi-Parametric Approach: A Technological Review Grigorios L. Kyriakopoulos, Vasilis C. Kapsalis, Konstantinos G. Aravossis, Miltiadis Zamparas and Alexandros Mitsikas, 2019, https://ideas.repec.org/a/gam/jsusta/v11y2019i21p6139-d283252.html

[14] Guidance for separate collection of municipal waste, Maarten Dubois, Edward Sims, Tim Moerman, David Watson, Bjorn Bauer, Jean-Benoît Bel, Georg Mehlhart, aprilie, 2020, https://ec.europa.eu/environment/waste/studies/pdf/15.1.\%20EC_DGENV_Separate\%20 Collection_guidance_DEF.pdf

[15] A roadmap towards a circular and sustainable bioeconomy through waste valorization, Maina, S., Kachrimanidou, V. And Koutinas, A. (2017), Current Opinion in Green and Sustainable Chemistry, 8. pp. 1823. ISSN 24522236 doi: https://doi.org/10.1016/j.cogsc.2017.07.007 http://centaur.reading.ac.uk/73361/.

[16] Biomass for biofuele, Strategies for Global Industries, Alain A. Vertes, Nasib Qureshi, Hans P. Blaschek, Hideaki Yukawa, ISBN 978-0-470-51312-5.

[17] Biocatalysis and biomass conversion: enabling a circular economy, Roger A. Sheldon, royalsocietypublishing.org/journal/rsta, 2019, https://dx.doi.org/10.1098/rsta.2019.0274.

[18] Study on estimating the potential for separate collection of biowaste suitable for treatment by anaerobic digestion and the potential for individual composting in Ilfov County, developer Sc Addvances Corp SRL, beneficiary Ilfov County - County Council, 2020. 